\title{
Review
}

\section{Treatment options for methicillin-resistant Staphylococcus aureus (MRSA) infection: Where are we now?}

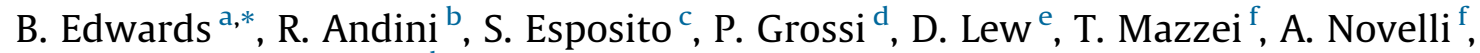 \\ A. Soriano ${ }^{g}$, I.M. Gould ${ }^{\mathrm{h}}$
}

\author{
${ }^{a}$ Medical Microbiology Department, Royal Infirmary of Edinburgh, 51 Little France Crescent, Dalkeith Road, Edinburgh EH16 4SA, UK \\ ${ }^{\mathrm{b}}$ Second University of Naples, UOC Transplant and Infectious Disease Medicine, AORN Monaldi, Naples, Italy \\ ${ }^{\mathrm{c}}$ Department of Medicine, University of Salerno, Salerno, Italy \\ d Department of Surgical and Morphological Studies, University of Unisubria, Varese, Italy \\ ${ }^{\mathrm{e}}$ Chief Infectious Diseases Division, Chief Department of Specialties of Internal Medicine, Geneva University Hospital, Geneva, Switzerland \\ ${ }^{\mathrm{f}}$ Department of Health Sciences, Clinical Pharmacology and Oncology Section, University of Firenze, Firenze, Italy \\ ${ }^{g}$ Department of Infectious Diseases, IDIBAPS, Hospital Clinic of Barcelona, Spain \\ ${ }^{\mathrm{h}}$ Medical Microbiology Department, Aberdeen Royal Infirmary, Aberdeen, UK
}

\section{A R T I C L E IN F O}

\section{Article history:}

Received 16 October 2013

Received in revised form 28 March 2014

Accepted 31 March 2014

\section{Keywords:}

MRSA

Treatment

Susceptibility testing

\begin{abstract}
A B S T R A C T
Methicillin-resistant Staphylococcus aureus (MRSA) infection continues to be a substantial global problem with significant associated morbidity and mortality. This review summarises the discussions that took place at the 4th MRSA Consensus Conference in relation to the current treatment options for serious MRSA infections and how to optimise whichever therapy is embarked upon. It highlights the many challenges faced by both the laboratory and clinicians in the diagnosis and treatment of MRSA infections.
\end{abstract}

(c) 2014 International Society for Chemotherapy of Infection and Cancer. Published by Elsevier Ltd. All rights reserved.

\section{Contents}

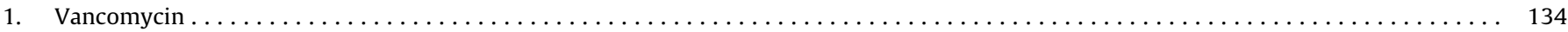

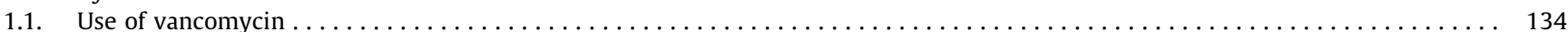

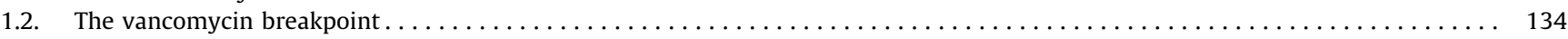

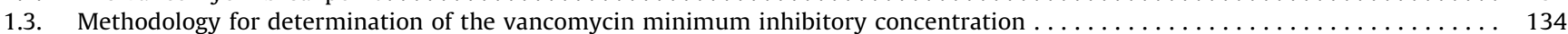

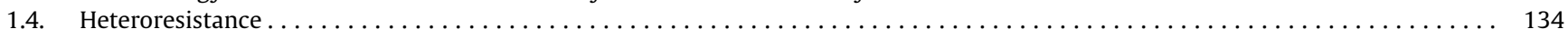

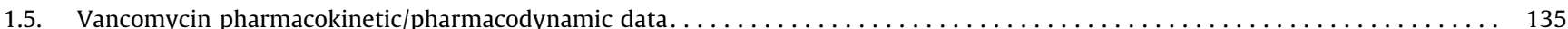

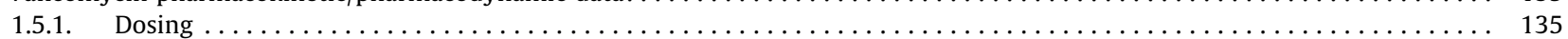

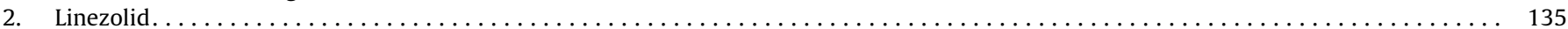

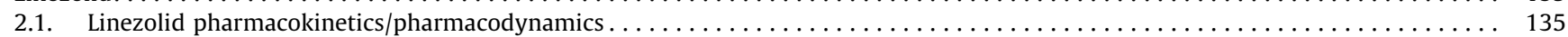

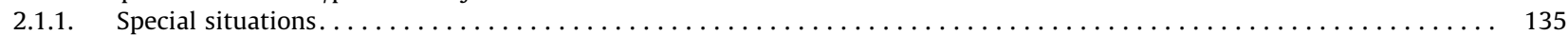

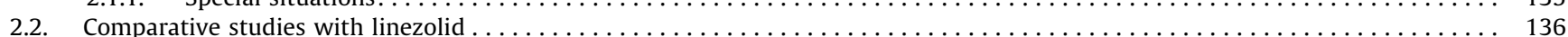

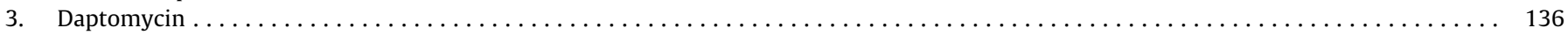

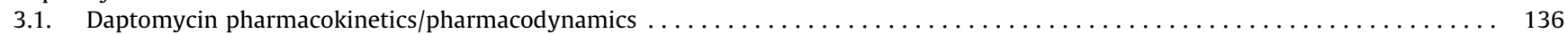

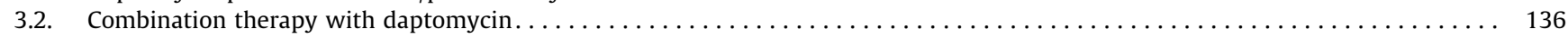

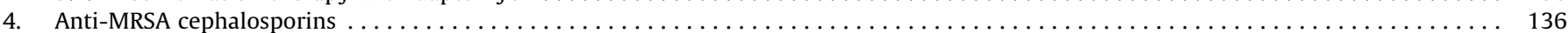

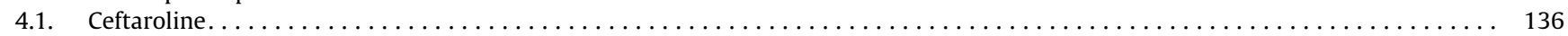

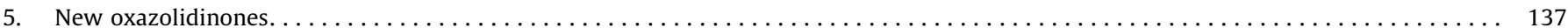

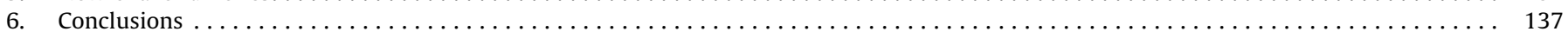

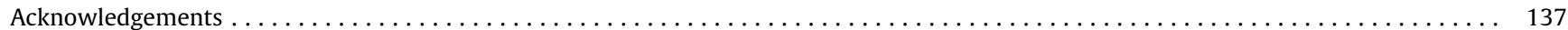

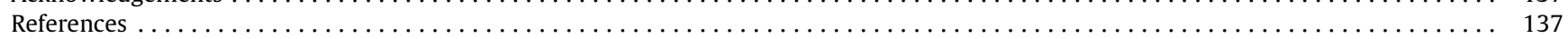

\footnotetext{
* Corresponding author. Tel.: +44 1312426069.

E-mail address: bex.edwards@gmail.com (B. Edwards).
} 


\section{Vancomycin}

\subsection{Use of vancomycin}

Vancomycin has been the drug of choice for treating severe infections due to methicillin-resistant Staphylococcus aureus (MRSA) during the last decades. Accumulating evidence of increasing resistance, unachievable pharmacokinetic/pharmacodynamic (PK/PD) targets and poorer outcomes challenges the suitability of the prime place of vancomycin in treatment regimens and guidelines [1-6].

Controversy still exists over the current, non-methoddependent breakpoint of $2 \mathrm{mg} / \mathrm{L}$, appreciating that if this were to be lowered further the majority of isolates would be deemed resistant [7]. A growing body of data showing significant variability both in minimum inhibitory concentration (MIC) measurements and accuracy of MIC determination demonstrates the importance of the method of susceptibility testing $[8,9]$.

\subsection{The vancomycin breakpoint}

The most recent guidelines on the treatment of MRSA published by the Infectious Diseases Society of America (IDSA) in 2011 give no information on the importance of an MIC within the susceptible range for clinical decision-making [10,11]. However, these were written in 2010 and evidence has continued to emerge since their inception and subsequent publication. Meta-analyses have consistently shown poorer outcomes with MICs approaching the breakpoint ( $>1 \mathrm{mg} / \mathrm{L}$ ), including mainly episodes of bacteraemia but also pneumonia and skin and soft-tissue infections (SSTIs) [12-14]. The vancomycin MIC was significantly associated with mortality for MRSA infection irrespective of the source of infection or MIC methodology [odds ratio $(\mathrm{OR})=1.64,95 \%$ confidence interval 1.14-2.37], although this was mostly attributable to bloodstream infections and Etest MICs of $2 \mathrm{mg} / \mathrm{L} \mathrm{[12].} \mathrm{It} \mathrm{is} \mathrm{acknowl-}$ edged that the data used for these meta-analyses are retrospective, that potential confounding factors were not controlled and that the MIC was measured with different techniques. To date, no randomised controlled studies have been performed to address this question, but there are three studies that have compared bacteraemic patients with infection due to MRSA with a vancomycin MIC $>1 \mathrm{mg} / \mathrm{L}$ and treated with daptomycin with a historical cohort of patients treated with vancomycin [15-17]. These studies demonstrated that daptomycin was superior to vancomycin in terms of clinical failure and mortality rate. Notwithstanding the limited data, it is difficult to ignore this message. For many, this is justification for lowering the breakpoint once again [2], although not all data support the association of MIC and worse outcome [18-21]. It is evident from a clinical perspective that there are many variables influencing the outcome of patients with $S$. aureus bacteraemia, including age, co-morbidity, severity of infection (severe sepsis or shock) and source of infection, but pharmacodynamic knowledge also supports the concept that it is difficult to achieve the pharmacodynamic target for vancomycin when the MIC is $>1 \mathrm{mg} / \mathrm{L}[22,23]$. Arguably, if the breakpoint was to be lowered to $>1 \mathrm{mg} / \mathrm{L}$, a significant proportion of isolates would become resistant, limiting therapeutic options still further. A potential solution would be to classify as intermediate those strains with a MIC $>1 \mathrm{mg} / \mathrm{L}$ and $\leq 2 \mathrm{mg} / \mathrm{L}$, inducing clinicians to judge the best option according to the clinical characteristics of the patients. The severity of infection can therefore be given due consideration.

\subsection{Methodology for determination of the vancomycin minimum inhibitory concentration}

There are limitations to the methodology for determining the vancomycin MIC in the clinical setting where cost, efficiency and clinically relevant turnaround times must be balanced appropriately. The gold-standard broth microdilution (BMD) method is out with the capacity for routine diagnostic use, thus commercial vancomycin MIC detection methods are used in most clinical diagnostic laboratories for susceptibility testing. Previously, investigations evaluating the precision of automated testing methods have used $\pm 1 \log _{2}$ dilution from the reference method as having essential agreement [8]. However, with a recent systematic review and meta-analysis showing greater failure rates and mortality with MICs of $1.5 \mathrm{mg} / \mathrm{L}$ or $2 \mathrm{mg} / \mathrm{L}$ (i.e. within 1 doubling dilution of the current breakpoint), the discrimination between susceptible and less susceptible isolates has become difficult and hence the precision of automated systems has come under greater scrutiny [12].

Recent reports describe discrepancies in the ability of automated systems to accurately determine the MIC of vancomycin against MRSA compared with Etest or reference BMD methods $[8,24]$. A recent study comparing four commercial MIC testing systems (MicroScan, VITEK ${ }^{\mathbb{R}} 2$, Phoenix and Etest) against the Clinical and Laboratory Standards Institute (CSLI) reference BMD method showed $61.8 \%, 54.3 \%, 66.2 \%$ and $36.7 \%$ absolute agreement ( $0 \pm$ dilution) with the BMD method, respectively [8]. Aside from the precision in determination of MICs, this study also highlights the risk of missing vancomycin MICs of $2 \mathrm{mg} / \mathrm{L}$ with certain automated systems by undercalling resistance, especially when heteroresistant vancomycin-intermediate $S$. aureus (hVISA) is involved [8]. Undercalling of resistance occurs both with the VITEK ${ }^{\circledR} 2$ and Phoenix systems, although the reason for discrepancies in accuracy between these systems is poorly understood, and given that these types of system are in widespread use it urges for caution in interpretation of susceptibility if infection is severe. Etest MIC determination, however, is often known to produce values that are 1 dilution higher than BMD, and this may prove a useful conservative estimate in evaluating vancomycin MICs when treating serious MRSA infections $[8,25,26]$. The practical difficulties in determining an MIC have led some to argue in favour of lowering the breakpoint as a pragmatic solution. If MICs were determined by Etest, conventional breakpoints could be retained, but the need for method-dependent breakpoints appears a reasonable stance to adopt, with a breakpoint of $>1.5 \mathrm{mg} / \mathrm{L}$ by Etest and $>1 \mathrm{mg} / \mathrm{L}$ by BMD.

\subsection{Heteroresistance}

hVISA is not associated with high mortality but with increased failure rates, suggesting that resistance may have a fitness cost [27-30]. According to this information, it would be interesting for the clinical management of severe $S$. aureus bacteraemia treated with vancomycin to know the presence of heteroresistance. However, laboratory determination of heteroresistance is difficult, with the gold-standard population analysis profiling being impracticable in the routine diagnostic laboratory. In the context of hVISA, teicoplanin antimicrobial sensitivity testing has been postulated as better predictor of heteroresistance and a better predictor of recurrence [31-33], but the literature is certainly far from clear on the issue of teicoplanin [34,35].

Aside from difficulties in detecting hVISA, there is uncertainty over the stability of resistance determinants, making the interpretation of techniques even more complex [36-38]. Most VISA appear to be unstable and lose this phenotype in the absence of selective pressure $[39,40]$. Currently, whether VISA and hVISA are absolute states or an expression of variability is unknown [41]. 
Mutations leading to resistance including agr, other polymorphisms and the expression of these, are another key area for ongoing research [42-45]. Until these mechanisms are more fully understood, current practice will consist of somewhat unsatisfactory phenotypic methods of resistance detection before molecular methods of resistance detection or certainty of susceptibility become available [28].

\subsection{Vancomycin pharmacokinetic/pharmacodynamic data}

\subsubsection{Dosing}

It is widely accepted that the ratio of the area under the concentration-time curve (AUC) to MIC (AUC/MIC) is the best pharmacodynamic predictor of vancomycin efficacy, and a value $\geq 400$ is associated with higher success rates in patients with respiratory tract infections [46] and bacteraemia [5] and $\geq 600$ in patients with septic shock [47]. These data support the recent guidelines for vancomycin dosing [22] that recommend a trough serum concentration of $\geq 15 \mathrm{mg} / \mathrm{L}$, supported by clinical data [48]. According to Monte Carlo simulation, this target is attainable only when the MIC of MRSA is $\leq 1 \mathrm{mg} / \mathrm{L}$ [23]. The recommended daily dose in order to attain the target is $15-20 \mathrm{mg} / \mathrm{kg}$ every $8-12 \mathrm{~h}$ if the patient has normal renal function [22]. A $25-30 \mathrm{mg} / \mathrm{kg}$ loading dose is recommended for critically ill patients. However, increased clearance and the need for haemofiltration, both common in critically ill patients, are associated with low serum concentrations [49-52] and difficulty in early achievement of the target.

To improve the efficacy of vancomycin, some authors propose administration by continuous infusion (CI). According to animal and clinical data, the AUC/MIC ratio is the best pharmacodynamic predictor of vancomycin efficacy; however, its bactericidal activity is time-dependent. Therefore, its administration by $\mathrm{CI}$ would be a reasonable mode of administration. CI of vancomycin in a pig lung model showed evidence for increased efficacy [53], but clinical experience is limited [54,55]. A clinical trial in intensive care unit (ICU) patients did not show better outcome using $\mathrm{CI}$ but it was associated with an earlier achievement of desired trough concentrations, and concentrations were more stable over time [56]. In addition, a meta-analysis showed decreased nephrotoxicity with CI [57]; however, patients included in some of the articles were outpatients and so with a lower risk of developing nephrotoxicity. A recent article including a large cohort of ICU patients receiving vancomycin by $\mathrm{CI}$ showed a rate of nephrotoxicity of $24 \%$, where the mean concentration of vancomycin within the first 3 days and the duration of treatment were independently associated with a higher risk of nephrotoxicity [58]. These data suggest that CI could be a potential administration mode for severe infections, but close monitoring of serum concentration and renal function is mandatory, most especially for patients with risk factors for nephrotoxicity (i.e. concomitant nephrotoxic drugs). There is no clinical experience using $\mathrm{CI}$ when the MIC is $>1 \mathrm{mg} / \mathrm{L}$ but the expected AUC with a plateau of $20-25 \mathrm{mg} / \mathrm{L}$ is $480-600 \mathrm{mg} \mathrm{h} / \mathrm{L}$. For an MIC of $1.5-$ $2 \mathrm{mg} / \mathrm{L}$ the ratio would be $240-400$, therefore below the required target to achieve a high success rate [59]. An experimental endocarditis model showed a high sterilisation rate using $\mathrm{CI}$ at $20 \mathrm{mg} / \mathrm{L}$ for MRSA with an MIC of $1 \mathrm{mg} / \mathrm{L}$ but a high failure rate and selection of strains with higher MICs using both $20 \mathrm{mg} / \mathrm{L}$ or $40 \mathrm{mg} / \mathrm{L}$ plateaus for infections due to MRSA strains with MICs of $2 \mathrm{mg} / \mathrm{L}$ and $8 \mathrm{mg} / \mathrm{L}$, respectively [60]. According to this information, for infections due to strains with an MIC $>1 \mathrm{mg} / \mathrm{L}$ it would be better to use an alternative antibiotic, particularly in severe infections.

Beyond the serum concentrations, it is known that vancomycin diffusion to some areas is low. For instance, concentrations in epithelial lining fluid [61] and in soft tissue of diabetic patients are low [62]. Taking into account the good diffusion of linezolid to poorly vascularised tissues, this difference could explain the superiority of linezolid over vancomycin in SSTIs in patients with vascular insufficiency described in a subanalysis of a previous randomised study [63]. These data suggest that in these clinical situations the vancomycin dose should be higher in order to achieve acceptable success rates.

Promoting higher doses promotes accepting nephrotoxicity, which requires an assessment of the level of concern and appropriate risk assessment [57]. An established link exists between vancomycin levels and renal toxicity, with van Hal et al. among others showing that if the vancomycin trough is $>20 \mathrm{mg} / \mathrm{L}$ toxicity is $33 \%$, and if it is $<20 \mathrm{mg} / \mathrm{L}$ then toxicity is $20 \%$, so levels ought to be measured [28,64]. A recent meta-analysis by van Hal et al. showed an increased probability of a nephrotoxic event not only with increasing trough concentrations but also length of exposure [28].

It is important that pharmacists advise clinicians if they are going to change from branded products to generics, or in the case of vancomycin between different generics. The World Health Organization (WHO) and drug regulatory agencies consider products for parental use a therapeutically equivalent if they are pharmaceutically equivalent [65]. Data showing significant differences in therapeutic equivalence in a neutropenic mouse model have previously caused concern [66]. However, a more recent study using a rabbit endocarditis model did not demonstrate any significant differences between different vancomycin generics, including those commonly used in the USA and Western Europe [67]. Where pharmaceutical parameters of equivalence allow for a range of $80-125 \%$ of the generic drug in serum concentrations compared with the branded drug, this has potential important consequences for antimicrobials such as vancomycin where MIC data suggest the need for doses approaching levels associated with increased toxicity [65].

\section{Linezolid}

\subsection{Linezolid pharmacokinetics/pharmacodynamics}

\subsubsection{Special situations}

2.1.1.1. Obesity. Data exist that support no need for increased dosing in patients weighing up to $150 \mathrm{~kg}$ [68]. However, in obese patients, observed serum levels have been lower than in the nonobese population, with one case report of a patient with a body mass index (BMI) of 37 describing clinical failure because of reduced serum concentration trough levels below the MIC $_{90}$ (MIC for $90 \%$ of the isolates) [69]. This suggests that there may be a need for increasing the dose in morbidly obese patients or in those $>50 \%$ of their calculated ideal body weight [69-71].

2.1.1.2. Critically ill patients. A linezolid trough $<2 \mathrm{mg} / \mathrm{L}$ was found in $29 \%$ of patients with sepsis [72], which was independently associated with an estimated glomerular filtration $>80 \mathrm{~mL} / \mathrm{min}$, typically found in patients with severe sepsis or septic shock [49]. The authors recommend a loading dose of $600 \mathrm{mg}$ three times daily for the first $24 \mathrm{~h}$, or the administration of the total daily dose by CI. Indeed, linezolid is stable and recent data demonstrated that $1200 \mathrm{mg} / 24 \mathrm{~h}$ by CI maintained concentrations between 7 and $10 \mathrm{mg} / \mathrm{L}$ and was associated with better pharmacodynamic parameters than intermittent administration of the same daily dose [73].

Administration of $1200 \mathrm{mg}$ by $\mathrm{CI}$ led to a steady-state concentration in epithelial lining fluid of $7 \mathrm{mg} / \mathrm{L} \mathrm{[74],} \mathrm{in}$ agreement with a diffusion rate of linezolid of $>90 \%$. Among critically ill patients, the need of extracorporeal membrane 
oxygenation has been associated with low serum concentrations in two of three patients, therefore when treating strains with an MIC of $2-4 \mathrm{mg} / \mathrm{L}$ the authors recommended either a loading dose or CI [75].

2.1.1.3. Concomitant use of rifampicin. The combination of linezolid and rifampicin is an attractive oral alternative in foreign-body infections; however, two studies performed in healthy volunteers have analysed this interaction and both articles showed a reduction of ca. $30 \%$ in the AUC of linezolid [76,77]. In addition, two cases of orthopaedic implant infections treated with this combination had a low linezolid serum concentration that was associated with clinical failure [78]. This is possibly explained because rifampicin induces P-glycoprotein, a transporter that increases the clearance of linezolid [79].

2.1.1.4. Prolonged use of linezolid. For the treatment of implant infections or tuberculosis it is necessary to prolong the administration of linezolid. Some data suggest that linezolid inhibits its own metabolism [80], therefore prolonged treatment is associated with a progressive increase in serum concentrations that are associated with haematological toxicity $[81,82]$. The linezolid toxic trough is not well defined but supposedly should not be $>8 \mathrm{mg} / \mathrm{L}$ (ideally 2-7 mg/L), and therapeutic drug monitoring (TDM) should probably be performed in certain circumstances [79,81]. A recent study analysed the trough concentrations in consecutive patients and found a mean trough of $9 \mathrm{mg} / \mathrm{L}$ in patients who developed haematological toxicity compared with $4 \mathrm{mg} / \mathrm{L}$ in those without toxicity [82].

2.1.1.5. Renal failure. Although linezolid requires no dose adjustment in renal failure, haematological toxicity was more frequent in patients with end-stage renal disease than in those with non-endstage renal disease $[83,84]$, and in a general population with sepsis a creatinine clearance of $<50 \mathrm{~mL} / \mathrm{min}$ was an independent predictor of thrombocytopenia [85]. It would be reasonable that linezolid clearance is decreased in patients with low glomerular filtration. Tsuji et al. [86] showed that the linezolid concentration was significantly higher than the predicted concentration in three patients with glomerular filtration $<40 \mathrm{~mL} / \mathrm{min}$, and severe thrombocytopenia developed as the linezolid concentration increased. These findings have recently been confirmed in a study that included 30 patients [87]. Thrombocytopenia occurred in 17 patients $(56.7 \%)$ and the median linezolid trough concentrations on Day 3 were significantly higher in patients with renal impairment than in patients without renal impairment (14.7 mg/L vs. $4.8 \mathrm{mg} / \mathrm{L} ; P=0.0001)$. Development of thrombocytopenia occurred significantly more frequently in patients with a linezolid trough concentration $>7.5 \mathrm{mg} / \mathrm{L}(\mathrm{OR}=90.0 ; P=0.0001)$ and renal impairment $(\mathrm{OR}=39.0 ; P=0.0002)$. These data suggest the need for close monitoring in these patients and to consider TDM.

\subsection{Comparative studies with linezolid}

Extracted patients from a phase 4 clinical trial of oral linezolid versus intravenous (i.v.) vancomycin with ischaemic/vascular problems showed that linezolid was better than vancomycin, with an OR of 4, probably due to better diffusion of linezolid to poorly vascularised tissues $[63,88]$.

In a randomised study, linezolid has demonstrated a higher success rate than vancomycin in nosocomial pneumonia due to MRSA (ZEPHyR study); however, mortality was similar in both arms and some authors criticised the vancomycin dosage [89-91], therefore there is still a debate in the literature about the first-line agent for MRSA pneumonia [92,93].

\section{Daptomycin}

\subsection{Daptomycin pharmacokinetics/pharmacodynamics}

The authors suggest a high dose of daptomycin $(8-10 \mathrm{mg} / \mathrm{kg})$ irrespective of the source of bacteraemia for the initial three doses [94]. If the infection is subsequently found to be uncomplicated, the dosage can then be reduced. A hard-hitting approach is recommended empirically. Although eosinophilic pneumonia has been reported, this appears to be rare and idiosyncratic.

\subsection{Combination therapy with daptomycin}

Limited, though accumulating, data exist for the use of combination therapy with daptomycin, including both animal models and in vitro data. Most available data exist on combination therapy with daptomycin and $\beta$-lactam antibiotics $[95,96]$. Oxacillin, in particular, appears to be very efficacious $[97,98]$. $\beta$ Lactams improve the binding of daptomycin by increasing the net negative charge of the cell membrane [96]. This may prevent the development of daptomycin resistance [96]. A recent article suggests that this benefit is particular for those $\beta$-lactams that bind to penicillin binding protein-1 (PBP1) [99].

Good data exist for the combination of daptomycin and trimethoprim/sulfamethoxazole, with recent case reports on the treatment of a Staphylococcus epidermidis meningitis and an MRSA complicated endocarditis [100,101]. Two cases of vertebral osteomyelitis reported by Avery et al. also show this combination favourably for isolates that are daptomycin-non-susceptible and vancomycin-intermediate [102].

High-dose daptomycin and fosfomycin have been used successfully in endocarditis, even for daptomycin-non-susceptible isolates $[103,104]$. Unfortunately, problems associated with i.v. fosfomycin supply in some European countries could render this option impractical.

Daptomycin and rifampicin is a good combination for infection involving prosthetic devices [105]. There are conflicting results in experimental models $[106,107]$ but recent clinical data in severe staphylococcal infections reported good results with this combination [108]. Interestingly, the authors found a good correlation between results of synergy using the chequerboard method and clinical outcome but not with killing curves. The combination has been recently retrospectively reviewed in 16 patients with orthopaedic infection with a success rate of 94\% [109].

Combination therapy avoids the development of resistance to daptomycin [110]. Combination therapy should therefore have potential in patients with endocarditis, undrainable abscesses and other high-inoculum infections. Knowing that daptomycin with oxacillin increases bactericidal activity and decreases the development of resistance [97] leads to speculation regarding potential advantages in empirical combination therapy.

\section{Anti-MRSA cephalosporins}

\subsection{Ceftaroline}

No new PK/PD data and no new clinical studies are available since the last consensus meeting in 2012. There have, however, been in vitro comparisons of ceftaroline versus linezolid, vancomycin and daptomycin showing equivalent efficacy where the ceftaroline MIC is $\leq 2 \mathrm{mg} / \mathrm{L}$ [111], and a study showing a potential role in isolates with reduced susceptibility to linezolid, daptomycin or vancomycin [112]. Data demonstrating adequate lung penetration [113] and also a case involving the clinical use of ceftaroline have been described [114]. 
PK/PD data demonstrate that in severe infections there is a need to achieve at least 50\% concentration higher than the MIC [115]. Ceftaroline epithelial lining fluid concentrations in a murine model were similar to serum concentrations, and exposures simulating human doses of $600 \mathrm{mg}$ twice daily achieved recommended pharmacodynamic targets [113]. Isolates with an MIC $>1 \mathrm{mg} / \mathrm{L}$ may require a dose increase, but there are no data to support this. Dosing at $600 \mathrm{mg}$ twice daily for SSTI appears reasonable, but the authors believe that in community-acquired pneumonia (CAP) dosing may not be high enough. Unfortunately there already exist Greek strains resistant to ceftaroline, so we can expect more strains to develop resistance [116]. The manufacturer may wish to look at higher dosing or modify the mode of administration, for instance, prolonged infusion, to combat/overcome this [117].

Being a $\beta$-lactam, ceftaroline has benefits in terms of decreased toxicity with good efficacy. There are, however, no clinical data on isolates with an MIC $>2 \mathrm{mg} / \mathrm{L}$. However, consideration still needs to be given to the exact clinical niche that ceftaroline will fill. There is some evidence to suggest that it may fulfil a role where there is reduced susceptibility to vancomycin, daptomycin or linezolid [112]. There is good experience in a few cases of bacteraemia, with one case of endocarditis showing sterility of vegetations at 13 days of therapy [114]. Ceftaroline has lower MICs than ceftriaxone for Streptococcus pneumoniae [118], but also offers broad-spectrum cover so could be used for Gram-negative infections. Ceftaroline has shown similar activity to ceftazidime for some Enterobacteriaceae [119]. The problem is that ceftaroline has the same pharmacokinetics as ceftazidime but we administer $2 \mathrm{~g} / 8 \mathrm{~h}$ of ceftazidime and only $600 \mathrm{mg} / 12 \mathrm{~h}$ of ceftaroline.

Ceftobiprole has a promising role in the treatment of hospitalacquired pneumonia. With efficacy similar to ceftazidime and cefepime against Pseudomonas spp., this would be a useful drug in the ventilator-associated pneumonia (VAP) subset [120]. However, at current dosing, conflicting data exist for the support of ceftobiprole use in VAP. Suggestions that ceftobiprole is unlikely to meet the desired pharmacodynamic targets when pharmacokinetic parameters are altered have been countered by Monte Carlo simulation based on phase 1 studies showing that target attainment is likely to be achieved, even in severely ill patients $[121,122]$. There needs to be a re-assessment of the quality of data for ceftobiprole use in SSTI, however the pneumonia data were of good quality. Ceftobiprole was recently shown to be non-inferior to linezolid and ceftriaxone for treating CAP [123].

\section{New oxazolidinones}

Tedizolid is currently only approved for SSTIs. However, it has demonstrated efficacy against wild-type and drug-resistant pathogens, including linezolid-resistant $S$. aureus strains with mutations both in chromosomal genes and ribosomal proteins [124].

\section{Conclusions}

Despite significant developments in the management and treatment of MRSA infection, many questions remain unanswered and the practical means to find solutions is challenging. Fundamental problems such as accurate determination of the MIC to the first-line antimicrobial agent are becoming apparent, as is the need to acknowledge the mode of susceptibility testing used. In the absence of a precise laboratory method that can predict the efficacy of vancomycin, it is understandable that newer agents will find favour over glycopeptides, particularly in severe infections where margins for error are narrow. Optimising all current therapies by dosing appropriately, and in certain circumstances considering combination therapy, will increase the efficacy of the antibiotics to hand and may lessen the potential for developing resistance.

\section{Funding}

Funding was received for the meeting by the International Society of Chemotherapy.

\section{Competing interests}

BE has received grant support and honoraria from Novartis; PG is a member of advisory boards for Novartis, Pfizer, MSD, AstraZeneca and Biotest and is a member of speakers' bureaux for Novartis, Pfize, MSD, Astellas, AstraZeneca, Biotest and Gilead; DL has, or had, links with Basilea, Pfizer and MSD; AN has received honoraria or grant support from AstraZeneca, MSD and Pfizer; AS is a speaker for Pfizer and Novartis and on the advisory boards of Pfizer and Novartis; IMG has consulted for and received lecturing fees from GSK, MSD, AstraZeneca, Novartis and Pfizer and has also consulted for Becton Dickinson, Astellas, bioMérieux, The Medicines Company, Cepheid and Cubist. In his capacity as President of the International Society of Chemotherapy, he is frequently requesting meeting support from a wide range of diagnostic and pharma companies, including many of those involved in the manufacture of diagnostics and antibiotics for MRSA. All other authors declare no competing interests.

\section{Ethical approval}

Not required.

\section{Acknowledgments}

The authors would like to thank all of the sponsors of the 4th International Society of Chemotherapy (ISC) MRSA Consensus Conference for their generous support.

\section{References}

[1] Bal AM, Garau J, Gould IM, Liao CH, Mazzei T, Nimmo GR, et al. Vancomycin in the treatment of methicillin-resistant Staphylococcus aureus (MRSA) infection: end of an era? J Glob Antimicrob Resist 2013;1:24-8.

[2] Gould IM. Is vancomycin redundant for serious staphylococcal infection? Int J Antimicrob Agents 2010;36(Suppl. 2):S55-7.

[3] van Hal SJ, Fowler Jr VG. Is it time to replace vancomycin in the treatment of methicillin-resistant Staphylococcus aureus infections? Clin Infect Dis 2013:56:1779-88.

[4] Holmes NE, Johnson PD, Howden BP. Relationship between vancomycinresistant Staphylococcus aureus, vancomycin-intermediate S. aureus, high vancomycin MIC, and outcome in serious S. aureus infections. J Clin Microbiol 2012:50:2548-52.

[5] Kullar R, Davis SL, Levine DP, Rybak MJ. Impact of vancomycin exposure on outcomes in patients with methicillin-resistant Staphylococcus aureus bacteremia: support for consensus guidelines suggested targets. Clin Infect Dis 2011;52:975-81.

[6] Soriano A, Marco F, Martínez JA, Pisos E, Almela M, Dimova VP, et al. Influence of vancomycin minimum inhibitory concentration on the treatment of methicillin-resistant Staphylococcus aureus bacteremia. Clin Infect Dis 2008;46:193-200

[7] Mohr JF, Murray BE, Point: 1. Vancomycin is not obsolete for the treatment of infection caused by methicillin-resistant Staphylococcus aureus. Clin Infect Dis 2007; $44: 1536-42$

[8] Rybak MJ, Vidaillac C, Sader HS, Rhomberg PR, Salimnia H, Briski LE, et al. Evaluation of vancomycin susceptibility testing for methicillin-resistant Staphylococcus aureus: comparison of Etest and three automated testing methods. J Clin Microbiol 2013;51:2077-81

[9] van Hal SJ, Barbagiannakos T, Jones M, Wehrhahn MC, Mercer J, Chen D, et al. Methicillin-resistant Staphylococcus aureus vancomycin susceptibility testing: methodology correlations, temporal trends and clonal patterns. J Antimicrob Chemother 2011;66:2284-7.

[10] Liu C, Bayer A, Cosgrove SE, Daum RS, Fridkin SK, Gorwitz RJ, et al. Clinical practice guidelines by the Infectious Diseases Society of America for the treatment of methicillin-resistant Staphylococcus aureus infections in adults and children: executive summary. Clin Infect Dis 2011;52:285-92. 
[11] Liu C, Bayer A, Cosgrove SE, Daum RS, Fridkin SK, Gorwitz RJ, et al. Infectious Diseases Society of America Clinical practice guidelines by the Infectious Diseases Society of America for the treatment of methicillin-resistant Staphylococcus aureus infections in adults and children. Clin Infect Dis 2011;52:e18-55.

[12] van Hal SJ, Lodise TP, Paterson DL. The clinical significance of vancomycin minimum inhibitory concentration in Staphylococcus aureus infections: a systematic review and meta-analysis. Clin Infect Dis 2012;54:755-71.

[13] Mavros MN, Tansarli GS, Vardakas KZ, Rafailidis PI, Karageorgopoulos DE, Falagas ME. Impact of vancomycin minimum inhibitory concentration on clinical outcomes of patients with vancomycin-susceptible Staphylococcus aureus infections: a meta-analysis and meta-regression. Int J Antimicrob Agents 2012;40:496-509.

[14] Jacob JT, DiazGranados CA. High vancomycin minimum inhibitory concentration and clinical outcomes in adults with methicillin-resistant Staphylococcus aureus infections: a meta-analysis. Int J Infect Dis 2013;17:e93-100.

[15] Moore CL, Osaki-Kiyan P, Haque NZ, Perri MB, Donabedian S, Zervos MJ. Daptomycin versus vancomycin for bloodstream infections due to methicillin-resistant Staphylococcus aureus with a high vancomycin minimum inhibitory concentration: a case-control study. Clin Infect Dis 2012;54:51-8.

[16] Murray KP, Zhao JJ, Davis SL, Kullar R, Kaye KS, Lephart P, et al. Early use of daptomycin versus vancomycin for methicillin-resistant Staphylococcus aureus bacteremia with vancomycin minimum inhibitory concentration $>1 \mathrm{mg} / \mathrm{L}$ : a matched cohort study. Clin Infect Dis 2013;56:1562-9.

[17] Cheng CW, Hsu PC, Yang CC, Chang HJ, Siu LK, Wu TL, et al. Influence of early daptomycin therapy on treatment outcome of methicillin-resistant Staphylococcus aureus bacteraemia with high vancomycin minimum inhibitory concentrations. Int J Antimicrob Agents 2013;41:293-4.

[18] Price J, Atkinson S, Llewelyn M, Paul J. Paradoxical relationship between the clinical outcome of Staphylococcus aureus bacteremia and the minimum inhibitory concentration of vancomycin. Clin Infect Dis 2009;48:997-8.

[19] Walraven CJ, North MS, Marr-Lyon L, Deming P, Sakoulas G, Mercier RC. Site of infection rather than vancomycin MIC predicts vancomycin treatment failure in methicillin-resistant Staphylococcus aureus bacteraemia. J Antimicrob Chemother 2011;66:2386-92.

[20] Rojas L, Bunsow E, Muñoz P, Cercenado E, Rodríguez-Créixems M, Bouza E. Vancomycin MICs do not predict the outcome of methicillin-resistant Staphylococcus aureus bloodstream infections in correctly treated patients. J Antimicrob Chemother 2012;67:1760-8.

[21] Hope R, Blackburn RM, Verlander NQ, Johnson AP, Kearns A, Hill R, et al. UK Clinical Infection Research Group Vancomycin MIC as a predictor of outcome in MRSA bacteraemia in the UK context. J Antimicrob Chemother 2013;68:2641-7.

[22] Rybak MJ, Lomaestro BM, Rotschafer JC, Moellering RC, Craig WA, Billeter M, et al. Vancomycin therapeutic guidelines: a summary of consensus recommendations from the Infectious Diseases Society of America, the American Society of Health-System Pharmacists, and the Society of Infectious Diseases Pharmacists. Clin Infect Dis 2009;49:325-7.

[23] Patel N, Pai MP, Rodvold KA, Lomaestro B, Drusano GL, Lodise TP. Vancomycin: we can't get there from here. Clin Infect Dis 2011;52:969-74.

[24] Hsu DI, Hidayat LK, Quist R, Hindler J, Karlsson A, Yusof A, et al. Comparison of method-specific vancomycin minimum inhibitory concentration values and their predictability for treatment outcome of methicillin-resistant Staphylococcus aureus (MRSA) infections. Int J Antimicrob Agents 2008;32:378-85.

[25] van Hal SJ, Paterson DL. Systematic review and meta-analysis of the significance of heterogeneous vancomycin-intermediate Staphylococcus aureus isolates. Antimicrob Agents Chemother 2011;55:405-10.

[26] Bland CM, Porr WH, Davis KA, Mansell KB. Vancomycin MIC susceptibility testing of methicillin-susceptible and methicillin-resistant Staphylococcus aureus isolates: a comparison between Etest ${ }^{\mathbb{R}}$ and an automated testing method. South Med J 2010;103:1124-8.

[27] van Hal SJ, Jones M, Gosbell IB, Paterson DL. Vancomycin heteroresistance is associated with reduced mortality in ST239 methicillin-resistant Staphylococcus aureus blood stream infections. PLoS ONE 2011;6:e21217.

[28] van Hal SJ, Paterson DL, Lodise TP. Systematic review and meta-analysis of vancomycin-induced nephrotoxicity associated with dosing schedules that maintain troughs between 15 and 20 milligrams per liter. Antimicrob Agents Chemother 2013;57:734-44.

[29] Park KH, Kim ES, Kim HS, Park SJ, Bang KM, Park HJ, et al. Comparison of the clinical features, bacterial genotypes and outcomes of patients with bacteraemia due to heteroresistant vancomycin-intermediate Staphylococcus aureus and vancomycin-susceptible S. aureus. J Antimicrob Chemother 2012;67:1843-9.

[30] Casapao AM, Leonard SN, Davis SL, Lodise TP, Patel N, Goff DA, et al. Clinical outcomes in patients with heterogeneous vancomycin-intermediate Staphylococcus aureus (hVISA) bloodstream infection. Antimicrob Agents Chemother )2013; (June) [Epub ahead of print].

[31] Uçkay I, Bernard L, Buzzi M, Harbarth S, François P, Huggler E, et al. High prevalence of isolates with reduced glycopeptide susceptibility in persistent or recurrent bloodstream infections due to methicillin-resistant Staphylococcus aureus. Antimicrob Agents Chemother 2012;56:1258-64.

[32] Chang HJ, Hsu PC, Yang CC, Siu LK, Kuo AJ, Chia JH, et al. Influence of teicoplanin MICs on treatment outcomes among patients with teicoplanin-treated methicillin-resistant Staphylococcus aureus bacteraemia: a hospital-based retrospective study. J Antimicrob Chemother 2012;67:736-41.
[33] Chen KY, Chang HJ, Hsu PC, Yang CC, Chia JH, Wu TL, et al. Relationship of teicoplanin MICs to treatment failure in teicoplanin-treated patients with methicillin-resistant Staphylococcus aureus pneumonia. J Microbiol Immunol Infect 2013;46:210-6.

[34] Richter SS, Satola SW, Crispell EK, Heilmann KP, Dohrn CL, Riahi F, et al. Detection of Staphylococcus aureus isolates with heterogeneous intermediate-level resistance to vancomycin in the United States. J Clin Microbiol 2011;49:4203-7.

[35] Satola SW, Farley MM, Anderson KF, Patel JB. Comparison of detection methods for heteroresistant vancomycin-intermediate Staphylococcus aure$u s$, with the population analysis profile method as the reference method. J Clin Microbiol 2011;49:177-83.

[36] Vaudaux P, Huggler E, Bernard L, Ferry T, Renzoni A, Lew DP. Underestimation of vancomycin and teicoplanin MICs by broth microdilution leads to underdetection of glycopeptide-intermediate isolates of Staphylococcus aureus. Antimicrob Agents Chemother 2010;54:3861-70.

[37] Swenson JM, Anderson KF, Lonsway DR, Thompson A, McAllister SK, Limbago $\mathrm{BM}$, et al. Accuracy of commercial and reference susceptibility testing methods for detecting vancomycin-intermediate Staphylococcus aureus. J Clin Microbiol 2009;47:2013-7.

[38] Sader HS, Jones RN, Rossi KL, Rybak MJ. Occurrence of vancomycin-tolerant and heterogeneous vancomycin-intermediate strains (hVISA) among Staphylococcus aureus causing bloodstream infections in nine USA hospitals. J Antimicrob Chemother 2009;64:1024-8.

[39] Howden BP, Davies JK, Johnson PD, Stinear TP, Grayson ML. Reduced vancomycin susceptibility in Staphylococcus aureus, including vancomycin-intermediate and heterogeneous vancomycin-intermediate strains: resistance mechanisms, laboratory detection, and clinical implications. Clin Microbiol Rev 2010;23:99-139.

[40] Moreillon P, Bizzini A, Giddey M, Vouillamoz J, Entenza JM. Vancomycinintermediate Staphylococcus aureus selected during vancomycin therapy of experimental endocarditis are not detected by culture-based diagnostic procedures and persist after treatment arrest. J Antimicrob Chemother 2012;67:652-60.

[41] Howden BP, Peleg AY, Stinear TP. The evolution of vancomycin intermediate Staphylococcus aureus (VISA) and heterogenous-VISA. Infect Genet Evol 2014;21:575-82.

[42] Mwangi MM, Wu SW, Zhou Y, Sieradzki K, de Lencastre H, Richardson P, et al. Tracking the in vivo evolution of multidrug resistance in Staphylococcus aureus by whole-genome sequencing. Proc Natl Acad Sci U S A 2007; 104:9451-6.

[43] Harigaya Y, Ngo D, Lesse AJ, Huang V, Tsuji BT. Characterization of heterogeneous vancomycin-intermediate resistance MIC and accessory gene regulator (agr) dysfunction among clinical bloodstream isolates of Staphylococcus aureus. BMC Infect Dis 2011;11:287.

[44] Hafer C, Lin Y, Kornblum J, Lowy FD, Uhlemann AC. Contribution of selected gene mutations to resistance in clinical isolates of vancomycin-intermediate Staphylococcus aureus. Antimicrob Agents Chemother 2012;56:5845-51.

[45] Takata T, Miyazaki M, Futo M, Hara S, Shiotsuka S, Kamimura H, et al. Presence of both heterogeneous vancomycin-intermediate resistance and $\beta$-lactam antibiotic-induced vancomycin resistance phenotypes is associated with the outcome in methicillin-resistant Staphylococcus aureus bloodstream infection. Scand J Infect Dis 2013;45:203-12.

[46] Moise-Broder PA, Forrest A, Birmingham MC, Schentag JJ. Pharmacodynamics of vancomycin and other antimicrobials in patients with Staphylococcus aureus lower respiratory tract infections. Clin Pharmacokinet 2004;43:925-42.

[47] Zelenitsky S, Rubinstein E, Ariano R, Iacovides H, Dodek P, Mirzanejad Y, et al. Cooperative Antimicrobial Therapy of Septic Shock - CATSS Database Research Group Vancomycin pharmacodynamics and survival in patients with methicillin-resistant Staphylococcus aureus-associated septic shock. Int J Antimicrob Agents 2013;41:255-60.

[48] Albur MS, Bowker K, Weir I, MacGowan A. Factors influencing the clinical outcome of methicillin-resistant Staphylococcus aureus bacteraemia. Eur J Clin Microbiol Infect Dis 2012;31:295-301.

[49] Claus BO, Hoste EA, Colpaert K, Robays H, Decruyenaere J, De Waele JJ. Augmented renal clearance is a common finding with worse clinical outcome in critically ill patients receiving antimicrobial therapy. J Crit Care 2013;28:695-700

[50] Ocampos-Martinez E, Penaccini L, Scolletta S, Abdelhadii A, Devigili A, Cianferoni S, et al. Determinants of early inadequate vancomycin concentrations during continuous infusion in septic patients. Int J Antimicrob Agents 2012;39:332-7.

[51] Petejova N, Martinek A, Zahalkova J, Duricova J, Brozmannova H, Urbanek K, et al. Vancomycin pharmacokinetics during high-volume continuous venovenous hemofiltration in critically ill septic patients. Biomed Pap Med Fac Univ Palacky Olomouc Czech Repub 2014;158:65-72.

[52] Frazee EN, Kuper PJ, Schramm GE, Larson SL, Kashani KB, Osmon DR, et al. Effect of continuous venovenous hemofiltration dose on achievement of adequate vancomycin trough concentrations. Antimicrob Agents Chemother 2012;56:6181-5.

[53] Martinez-Olondris P, Rigol M, Soy D, Guerrero L, Agusti C, Quera MA, et al. Efficacy of linezolid compared to vancomycin in an experimental model of pneumonia induced by methicillin-resistant Staphylococcus aureus in ventilated pigs. Crit Care Med 2012;40:162-8. 
[54] Rello J, Sole-Violan J, Sa-Borges M, Garnacho-Montero J, Muñoz E, Sirgo G, et al. Pneumonia caused by oxacillin-resistant Staphylococcus aureus treated with glycopeptides. Crit Care Med 2005;33:1983-7.

[55] Verrall AJ, Llorin R, Tam VH, Lye DC, Sulaiman Z, Zhong L, et al. Efficacy of continuous infusion of vancomycin for the outpatient treatment of methicillin-resistant Staphylococcus aureus infections. J Antimicrob Chemother 2012;67:2970-3

[56] Wysocki M, Delatour F, Faurisson F, Rauss A, Pean Y, Misset B, et al. Continuous versus intermittent infusion of vancomycin in severe staphylococca infections: prospective multicenter randomized study. Antimicrob Agents Chemother 2001;45:2460-7.

[57] Cataldo MA, Tacconelli E, Grilli E, Pea F, Petrosillo N. Continuous versus intermittent infusion of vancomycin for the treatment of Gram-positive infections: systematic review and meta-analysis. J Antimicrob Chemother 2012;67:17-24.

[58] Cianferoni S, Devigili A, Ocampos-Martinez E, Penaccini L, Scolletta S, Abdelhadii $\mathrm{A}$, et al. Development of acute kidney injury during continuous infusion of vancomycin in septic patients. Infection 2013;41:811-20.

[59] Panday PN, Sturkenboom M. Continuous infusion of vancomycin less effective and safe than intermittent infusion, based on pharmacodynamic and pharmacokinetic principles. Clin Infect Dis 2009;49:1964-5.

[60] Entenza JM, Veloso TR, Vouillamoz J, Giddey M, Moreillon P. Failure of vancomycin continuous infusion against experimental endocarditis due to vancomycin-intermediate Staphylococcus aureus. Antimicrob Agents Chemother 2011;55:385-7.

[61] Lodise TP, Drusano GL, Butterfield JM, Scoville J, Gotfried M, Rodvold KA Penetration of vancomycin into epithelial lining fluid in healthy volunteers. Antimicrob Agents Chemother 2011;55:5507-11.

[62] Skhirtladze K, Hutschala D, Fleck T, Thalhammer F, Ehrlich M, Vukovich T, et al. Impaired target site penetration of vancomycin in diabetic patients following cardiac surgery. Antimicrob Agents Chemother 2006;50:1372-5.

[63] Duane TM, Weigelt JA, Puzniak LA, Huang DB. Linezolid and vancomycin in treatment of lower-extremity complicated skin and skin structure infections caused by methicillin-resistant Staphylococcus aureus in patients with and without vascular disease. Surg Infect (Larchmt) 2012;13:147-53.

[64] Horey A, Mergenhagen KA, Mattappallil A. The relationship of nephrotoxicity to vancomycin trough serum concentrations in a veteran's population: retrospective analysis. Ann Pharmacother 2012;46:1477-83.

[65] World Health Organization. WHO Expert Committee on specifications for pharmaceutical preparations. Geneva, Switzerland: WHO; 2006. p. 347-90, Technical Report Series No. 937 Annex 7.

[66] Vesga O, Agudelo M, Salazar BE, Rodriguez CA, Zuluaga AF. Generic vancomycin products fail in vivo despite being pharmaceutical equivalents of the innovator. Antimicrob Agents Chemother 2010;54:3271-9.

[67] Tattevin P, Saleh-Mghir A, Davido B, Ghout I, Massias L, Garcia de la Maria C, et al. Comparison of six generic vancomycin products for treatment of methicillin-resistant Staphylococcus aureus experimental endocarditis in rabbits. Antimicrob Agents Chemother 2013;57:1157-62.

[68] Bhalodi AA, Papasavas PK, Tishler DS, Nicolau DP, Kuti JL. Pharmacokinetics of intravenous linezolid in moderately to morbidly obese adults. Antimicrob Agents Chemother 2013;57:1144-9.

[69] Tsuji Y, Hiraki Y, Matsumoto K, Mizoguchi A, Sadoh S, Kobayashi T, et al Evaluation of the pharmacokinetics of linezolid in an obese Japanese patient. Scand J Infect Dis 2012;44:626-9.

[70] Muzevich KM, Lee KB. Subtherapeutic linezolid concentrations in a patient with morbid obesity and methicillin-resistant Staphylococcus aureus pneumonia: case report and review of the literature. Ann Pharmacother 2013;47:e25.

[71] Dryden MS. Linezolid pharmacokinetics and pharmacodynamics in clinical treatment. J Antimicrob Chemother 2011;66(Suppl. 4):iv7-15.

[72] Morata L, Cuesta M, Rojas JF, Rodriguez S, Brunet M, Casals G, et al. Risk factors for a low linezolid trough plasma concentration in acute infections. Antimicrob Agents Chemother 2013:57:1913-7.

[73] Adembri C, Fallani S, Cassetta MI, Arrigucci S, Ottaviano A, Pecile P, et al. Linezolid pharmacokinetic/pharmacodynamic profile in critically ill septic patients: intermittent versus continuous infusion. Int J Antimicrob Agents 2008;31:122-9

[74] Boselli E, Breilh D, Caillault-Sergent A, Djabarouti S, Guillaume C, Xuereb F, et al. Alveolar diffusion and pharmacokinetics of linezolid administered in continuous infusion to critically ill patients with ventilator-associated pneumonia. J Antimicrob Chemother 2012;67:1207-10.

[75] De Rosa FG, Corcione S, Baietto L, Ariaudo A, Di Perri G, Ranieri VM, et al. Pharmacokinetics of linezolid during extracorporeal membrane oxygenation. Int J Antimicrob Agents 2013;41:590-1.

[76] Gandelman K, Zhu T, Fahmi OA, Glue P, Lian K, Obach RS, et al. Unexpected effect of rifampin on the pharmacokinetics of linezolid: in silico and in vitro approaches to explain its mechanism. J Clin Pharmacol 2011;51:229-36.

[77] Egle H, Trittler R, Kümmerer K, Lemmen SW. Linezolid and rifampin: drug interaction contrary to expectations? Clin Pharmacol Ther 2005;77:451-3.

[78] Hoyo I, Martínez-Pastor J, Garcia-Ramiro S, Climent C, Brunet M, Cuesta M et al. Decreased serum linezolid concentrations in two patients receiving linezolid and rifampicin due to bone infections. Scand J Infect Dis 2012;44:548-50

[79] Pea F, Viale P, Cojutti P, Del Pin B, Zamparini E, Furlanut M. Therapeutic drug monitoring may improve safety outcomes of long-term treatment with linezolid in adult patients. J Antimicrob Chemother 2012;67:2034-42.
[80] Di Paolo A, Malacarne P, Guidotti E, Danesi R, Del Tacca M. Pharmacological issues of linezolid: an updated critical review. Clin Pharmacokinet 2010;49:439-47.

[81] Pea F, Furlanut M, Cojutti P, Cristini F, Zamparini E, Franceschi L, et al. Therapeutic drug monitoring of linezolid: a retrospective monocentric analysis. Antimicrob Agents Chemother 2010;54:4605-10.

[82] Cattaneo D, Orlando G, Cozzi V, Cordier L, Baldelli S, Merli S, et al. Linezolid plasma concentrations and occurrence of drug-related haematological toxicity in patients with Gram-positive infections. Int J Antimicrob Agents 2013;41:586-9.

[83] Wu VC, Wang YT, Wang CY, Tsai IJ, Wu KD, Hwang JJ, et al. High frequency of linezolid-associated thrombocytopenia and anemia among patients with end-stage renal disease. Clin Infect Dis 2006;42:66-72.

[84] Lin YH, Wu VC, Tsai IJ, Ho YL, Hwang JJ, Tsau YK, et al. High frequency of linezolid-associated thrombocytopenia among patients with renal insufficiency. Int J Antimicrob Agents 2006;28:345-51.

[85] Takahashi Y, Takesue Y, Nakajima K, Ichiki K, Wada Y, Tsuchida T, et al. Implementation of a hospital-wide project for appropriate antimicrobial prophylaxis. J Infect Chemother 2010;16:418-23.

[86] Tsuji Y, Hiraki Y, Matsumoto K, Mizoguchi A, Kobayashi T, Sadoh S, et al. Thrombocytopenia and anemia caused by a persistent high linezolid concentration in patients with renal dysfunction. J Infect Chemother 2011;17: $70-5$.

[87] Nukui Y, Hatakeyama S, Okamoto K, Yamamoto T, Hisaka A, Suzuki H, et al. High plasma linezolid concentration and impaired renal function affect development of linezolid-induced thrombocytopenia. J Antimicrob Chemother 2013;68:2128-33.

[88] Itani KM, Biswas P, Reisman A, Bhattacharyya H, Baruch AM. Clinical efficacy of oral linezolid compared with intravenous vancomycin for the treatment of methicillin-resistant Staphylococcus aureus-complicated skin and soft tissue infections: a retrospective, propensity score-matched, case-control analysis. Clin Ther 2012;34:1667-73.

[89] Wolff M, Mourvillier B. Linezolid for the treatment of nosocomial pneumonia due to methicillin-resistant Staphylococcus aureus. Clin Infect Dis 2012;55: 160-1.

[90] Taccone FS, Vincent JL, Denis O, Jacobs F. Should we abandon vancomycin for treatment of methicillin-resistant Staphylococcus aureus pneumonia? Still questions to answer. Clin Infect Dis 2012;55:161-3.

[91] Masuta K, Oba Y, Iwata K. Linezolid versus vancomycin for methicillinresistant Staphylococcus aureus nosocomial pneumonia: controversy continues. Clin Infect Dis 2012;55:161.

[92] Alaniz C, Pogue JM. Vancomycin versus linezolid in the treatment of methicillin-resistant Staphylococcus aureus nosocomial pneumonia: implications of the ZEPHyR trial. Ann Pharmacother 2012;46:1432-5.

[93] Pletz MW, Burkhardt O, Welte T. Nosocomial methicillin-resistant Staphylococcus aureus (MRSA) pneumonia: linezolid or vancomycin? Comparison of pharmacology and clinical efficacy. Eur J Med Res 2010;15: 507-13.

[94] Gould IM, Miró JM, Rybak MJ. Daptomycin: the role of high-dose and combination therapy for Gram-positive infections. Int J Antimicrob Agents 2013;42:202-10.

[95] Dhand A, Bayer AS, Pogliano J, Yang SJ, Bolaris M, Nizet V, et al. Use of antistaphylococcal $\beta$-lactams to increase daptomycin activity in eradicating persistent bacteremia due to methicillin-resistant Staphylococcus aureus: role of enhanced daptomycin binding. Clin Infect Dis 2011:53:158-63.

[96] Moise PA, Amodio-Groton M, Rashid M, Lamp KC, Hoffman-Roberts HL, Sakoulas G, et al. Multicenter evaluation of the clinical outcomes of daptomycin with and without concomitant $\beta$-lactams in patients with Staphylococcus aureus bacteremia and mild to moderate renal impairment. Antimicrob Agents Chemother 2013;57:1192-200.

[97] Rand KH, Houck HJ. Synergy of daptomycin with oxacillin and other $\beta$-lactams against methicillin-resistant Staphylococcus aureus. Antimicrob Agents Chemother 2004;48:2871-5.

[98] Yang SJ, Xiong YQ, Boyle-Vavra S, Daum R, Jones T, Bayer AS. Daptomycinoxacillin combinations in treatment of experimental endocarditis caused by daptomycin-nonsusceptible strains of methicillin-resistant Staphylococcus aureus with evolving oxacillin susceptibility (the 'seesaw effect'). Antimicrob Agents Chemother 2010;54:3161-9.

[99] Berti AD, Sakoulas G, Nizet V, Tewhey R, Rose WE. $\beta$-Lactam antibiotics targeting PBP1 selectively enhance daptomycin activity against methicillinresistant Staphylococcus aureus. Antimicrob Agents Chemother 2013:57:5005-12.

[100] Vena A, Falcone M, Comandini E, Meledandri M, Novelli A, Campanile F, et al. Daptomycin plus trimethoprim/sulfamethoxazole combination therapy in post-neurosurgical meningitis caused by linezolid-resistant Staphylococcus epidermidis. Diagn Microbiol Infect Dis 2013;76:99-102.

[101] Di Carlo P, D’Alessandro N, Guadagnino G, Bonura C, Mammina C, Lunetta M, et al. High dose of trimethoprim-sulfamethoxazole and daptomycin as a therapeutic option for MRSA endocarditis with large vegetation complicated by embolic stroke: a case report and literature review. Infez Med 2013;21: 45-9.

[102] Avery LM, Steed ME, Woodruff AE, Hasan M, Rybak MJ. Daptomycin-nonsusceptible vancomycin-intermediate Staphylococcus aureus vertebral osteomyelitis cases complicated by bacteremia treated with high-dose daptomycin and trimethoprim-sulfamethoxazole. Antimicrob Agents Chemother 2012;56:5990-3. 
[103] Miró JM, Entenza JM, Del Río A, Velasco M, Castañeda X, Garcia de la Mària C, et al. Hospital Clinic Experimental Endocarditis Study Group High-dose daptomycin plus fosfomycin is safe and effective in treating methicillinsusceptible and methicillin-resistant Staphylococcus aureus endocarditis. Antimicrob Agents Chemother 2012;56:4511-5.

[104] Chen LY, Huang CH, Kuo SC, Hsiao CY, Lin ML, Wang FD, et al. High-dose daptomycin and fosfomycin treatment of a patient with endocarditis caused by daptomycin-nonsusceptible Staphylococcus aureus: case report. BMC Infect Dis 2011;11:152

[105] Garrigós C, Murillo O, Euba G, Verdaguer R, Tubau F, Cabellos C, et al. Efficacy of usual and high doses of daptomycin in combination with rifampin versus alternative therapies in experimental foreign-body infection by methicillinresistant Staphylococcus aureus. Antimicrob Agents Chemother 2010;54: $5251-6$.

[106] Miró JM, García-de-la-Mària C, Armero Y, Soy D, Moreno A, del Río A, et al. Hospital Clinic Experimental Endocarditis Study Group Addition of gentamicin or rifampin does not enhance the effectiveness of daptomycin in treatment of experimental endocarditis due to methicillin-resistant Staphylococcus aureus. Antimicrob Agents Chemother 2009;53:4172-7.

[107] Parra-Ruiz J, Vidaillac C, Rose WE, Rybak MJ. Activities of high-dose daptomycin, vancomycin, and moxifloxacin alone or in combination with clarithromycin or rifampin in a novel in vitro model of Staphylococcus aureus biofilm. Antimicrob Agents Chemother 2010;54:4329-34.

[108] Rose WE, Berti AD, Hatch JB, Maki DG. Relationship of in vitro synergy and treatment outcome with daptomycin plus rifampin in patients with invasive methicillin-resistant Staphylococcus aureus infections. Antimicrob Agents Chemother 2013;57:3450-2.

[109] Jugun K, Vaudaux P, Garbino J, Pagani L, Hoffmeyer P, Lew D, et al. The safety and efficacy of high-dose daptomycin combined with rifampicin for the treatment of Gram-positive osteoarticular infections. Int Orthop 2013;37: $1375-80$.

[110] Lefebvre M, Jacqueline C, Amador G, Le Mabecque V, Miegeville A, Potel G, et al. Efficacy of daptomycin combined with rifampicin for the treatment of experimental methicillin-resistant Staphylococcus aureus (MRSA) acute osteomyelitis. Int J Antimicrob Agents 2010;36:542-4.

[111] Mélard A, Garcia LG, Das D, Rozenberg R, Tulkens PM, Van Bambeke F, et al. Activity of ceftaroline against extracellular (broth) and intracellular (THP-1 monocytes) forms of methicillin-resistant Staphylococcus aureus: comparison with vancomycin, linezolid and daptomycin. J Antimicrob Chemother 2013;68:648-58

[112] Sader HS, Flamm RK, Jones RN. Antimicrobial activity of ceftaroline tested against staphylococci with reduced susceptibility to linezolid, daptomycin, or vancomycin from U.S. hospitals, 2008 to 2011. Antimicrob Agents Chemother 2013;57:3178-81.
[113] Bhalodi AA, Crandon JL, Biek D, Nicolau DP. Efficacy of ceftaroline fosamil in a staphylococcal murine pneumonia model. Antimicrob Agents Chemother 2012;56:6160-5.

[114] Ho TT, Cadena J, Childs LM, Gonzalez-Velez M, Lewis JS 2nd. Methicillinresistant Staphylococcus aureus bacteraemia and endocarditis treated with ceftaroline salvage therapy. J Antimicrob Chemother 2012;67: $1267-70$

[115] MacGowan AP, Noel AR, Tomaselli S, Bowker KE. Pharmacodynamics of ceftaroline against Staphylococcus aureus studied in an in vitro pharmacokinetic model of infection. Antimicrob Agents Chemother 2013;57: 2451-6.

[116] Mendes RE, Tsakris A, Sader HS, Jones RN, Biek D, McGhee P, et al. Characterization of methicillin-resistant Staphylococcus aureus displaying increased MICs of ceftaroline. J Antimicrob Chemother 2012;67:1321-4.

[117] Ikeda Y, Ban J, Ishikawa T, Hashiguchi S, Urayama S, Horibe H. Stability and stabilization studies of TAK-599 (ceftaroline fosamil), a novel N-phosphono type prodrug of anti-methicillin resistant Staphylococcus aureus cephalosporin T-91825. Chem Pharm Bull (Tokyo) 2008;56:1406-11.

[118] Shorr AF, Kollef M, Eckburg PB, Llorens L, Friedland HD. Assessment of ceftaroline fosamil in the treatment of community-acquired bacterial pneumonia due to Streptococcus pneumoniae: insights from two randomized trials. Diagn Microbiol Infect Dis 2013;75:298-303.

[119] Farrell DJ, Flamm RK, Sader HS, Jones RN. Spectrum and potency of ceftaroline tested against leading pathogens causing skin and soft-tissue infections in Europe (2010). Int J Antimicrob Agents 2013;41:337-42.

[120] Flamm RK, Sader HS, Streit JM, Jones RN. Activity of ceftobiprole tested against pathogens associated with hospital-acquired bacterial pneumonia in Europe. In: 23rd European Congress of Clinical Microbiology and Infectious Diseases (ECCMID); 2013 [P1625].

[121] Muller AE Schmitt-Hoffmann AH, Punt N, Mouton JW. Monte Carlo simulations based on phase 1 studies predict target attainment of ceftobiprole in nosocomial pneumonia patients: a validation study. Antimicrob Agents Chemother 2013;57:2047-53.

[122] Lagacé-Wiens PR, Rubinstein E. Pharmacokinetic and pharmacodynamics evaluation of ceftobiprole medocaril for the treatment of hospital-acquired pneumonia. Expert Opin Drug Metab Toxicol 2013;9:789-99.

[123] Nicholson SC, Welte T, File Jr TM, Strauss RS, Michiels B, Kaul P, et al. A randomised, double-blind trial comparing ceftobiprole medocaril with ceftriaxone with or without linezolid for the treatment of patients with community-acquired pneumonia requiring hospitalisation. Int J Antimicrob Agents 2012;39:240-6.

[124] Locke JB, Zurenko GE, Shaw KJ, Bartizal K. Tedizolid for the management of human infections: in vitro characteristics. Clin Infect Dis 2014 58(Suppl. 1):S35-42. 